\title{
DFT Calculations Investigate Competing Pathways to Form Dimeric Neopentylpalladium(II) Amido Complexes
}

\author{
Quan Jiang, ${ }^{\dagger, \pi}$ Thomas R. Cundari ${ }^{* *}$
}

† Department of Chemistry and Center for Advanced Scientific Computing and Modeling, University of North Texas, Denton, Texas 76203, United States

ABSTRACT: Computational methods were utilized to study the formation of a dimeric neopentylpalladium(II) amido complex (D). The dimeric core of $\mathbf{D}$ contains asymmetric bridging of the anilide groups. Electron density analyses indicate that each palladium center of $\mathbf{D}$ forms a dative bond to the nitrogen trans to the coordinated phosphine, while the bond to the nitrogen cis to the phosphine lies closer to the covalent regime. Analysis of the structure of $\mathbf{D}$ was corroborated by study of the frontier orbitals and the energetics of dimerization. $\mathbf{D}$ was likely generated by the monomers with cis $\mathrm{P}, \mathrm{N}$ configuration rather than those with trans $\mathrm{P}, \mathrm{N}$ configuration, which is an important side reaction that inhibits the desired C-N bond coupling. Calculations further revealed the critical importance of dispersion interactions upon dimerization and suggested one possible dimeric isomer $\mathbf{Q}$.

\section{INTRODUCTION}

Dimeric metal complexes with an $\mathrm{M}_{2}(\mu-\mathrm{L})_{2}$ (M: metal; L: bridging element) ring are common in chemistry. ${ }^{1-4}$ Spectroscopic methods indicated that many of these dimers exist as mixtures of isomers, which have been attributed to the substituents attached to the ring. ${ }^{5-17}$ However, the M-L bonds within the dimeric core can be different in nature, which could impact the spectroscopic results as well. Meanwhile, the orbital interactions within the core vary depending on the distance between $\mathrm{M}$ atoms. ${ }^{2}$ Transition metal complexes with nitrogencontaining ligands are well-known and have drawn considerable attention for decades in catalyzing versatile reactions such as the palladium-catalyzed amination of aryl halides. ${ }^{18-24}$ Given available lone-pair electrons, many nitrogen-based ligands may coordinate to an additional metal center, leading to dimeric complexes with a core fourmembered ring. For instance, Driver and Hartwig reported the reductive elimination from dimeric palladium amido complexes (Figure 1a). 8

Recently, our groups reported the synthesis of phosphineligated neopentylpalladium(II) amido complexes that underwent reductive elimination to form $\mathrm{C}_{\mathrm{sp} 3}-\mathrm{N}$ bonds. ${ }^{23} \mathrm{We}$ attempted to synthesize the complex $1\left(\mathrm{Ad}_{2} \mathrm{PCH}_{2} \mathrm{CH}_{2} \mathrm{OCH}_{3}-\right.$ $\left.\kappa^{2} \mathrm{P}, \mathrm{O}\right) \mathrm{Pd}\left(\right.$ neopentyl) $\mathrm{NH}\left(4-\mathrm{F}-2-\left(\mathrm{OCH}_{3}\right)-\mathrm{C}_{6} \mathrm{H}_{3}, \quad\right.$ Figure 1b) containing a flexible $\mathrm{P}, \mathrm{O}$ ligand and an anilido ligand. However, this complex was isolated in a mixture with its dimer $\mathbf{D}$, and recrystallization of this mixture yielded crystals of pure D suitable for X-ray diffraction. Kinetic measurements indicated that $\mathbf{1}$, but not $\mathbf{D}$, underwent reductive elimination. These experimental results suggested that $\mathbf{D}$ is more stable than $\mathbf{1}$. According to a search of the Cambridge Structure Database, D is the first structurally characterized example of a dimeric phosphine-ligated alkylpalladium(II) amido complex. ${ }^{25}$ Furthermore, the formation of stable dimeric Pd(II) complexes could be an unproductive decomposition pathway that hinders both fundamental studies on the rare $\mathrm{C}_{\mathrm{sp} 3} \mathrm{-N}$ bond-forming reductive elimination and thus the development of catalytic reactions involving alkylpalladium(II) amido complexes. ${ }^{20-24}$ Considering both the unique structure of this complex and its potential impact on further work, we chose to investigate the dimeric Pd(II) complex D more closely with DFT (density functional theory) and sought to understand its bonding and the factors that control its formation. a) "Butterfly" dimers:

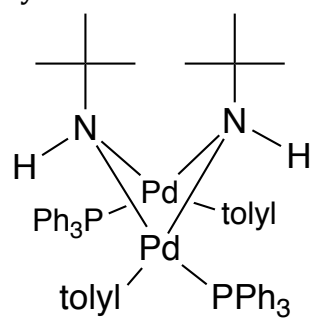

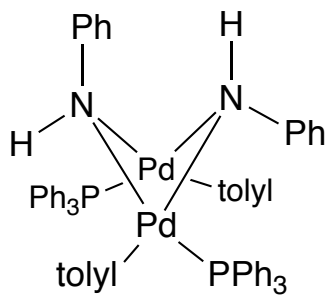

b) Our previous work: monomer $\mathbf{1}$ and dimer $\mathbf{D}^{*}$

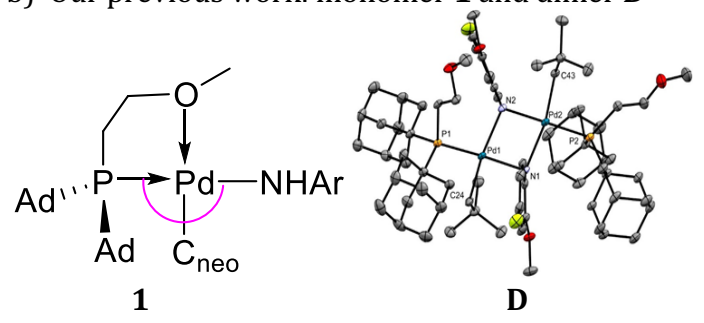

c) This work: Path I and II leading to D

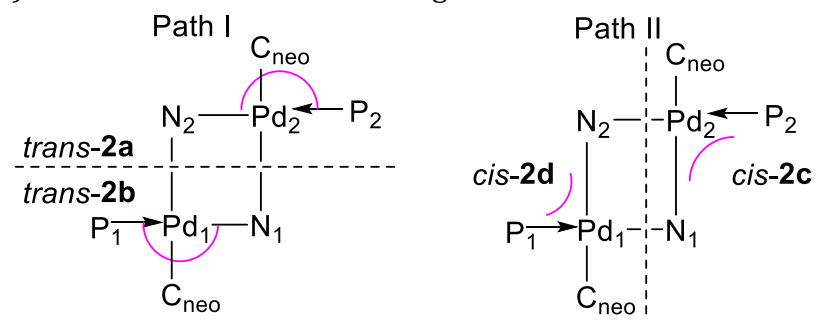

Figure 1. Ar: 4-F-2-(OCH 3$)-\mathrm{C}_{6} \mathrm{H}_{3}$. Ad: 1-adamantyl. $\mathrm{C}_{\text {neo: }}$ : neopentyl. Purple line: the angle of P-Pd-N. *Adapted with permission from reference 23.

In this work, computational analyses of the structure of the dimeric neopentylpalladium(II) amido complex $\mathbf{D}$ and the possible competing mechanisms for its formation are reported. Conceptually, the dimeric structure of $\mathbf{D}$ can be divided in two different ways, which suggest two possible general pathways of dimerization (Figure 1c). Path I starts with two monomeric neopentylpalladium(II) amido complexes trans-2a and trans$\mathbf{2 b}$, which are conformers related by rotation of the P-Pd bond. Each of these fragments has a geometry with trans phosphine and anilide ligands, and thus the alkyl group is trans to either an open coordination site of the T-shaped monomer or perhaps the weakly coordinating $-\mathrm{CH}_{2} \mathrm{CH}_{2} \mathrm{OMe}$ arm (as in 1). This is contrasted by the monomeric conformers cis-2c and cis-2d in Path II, which place the phosphine trans to the open 
coordination site of a T-shaped monomer. We investigated potential intermediates along both of these pathways, and determined the impact of dispersion effects on the relative energies of these complexes. Calculations further suggest that the arrangement of dative and covalent $\mathrm{M}-\mathrm{L}$ bonds within the four-membered core of $\mathbf{D}$ contrasts those of the stable trans monomeric complexes, and this difference in bonding might explain why $\mathbf{1}$ undergoes reductive elimination more readily than dimerization.

\section{COMPUTATIONAL METHODS}

DFT calculations were carried out using the Gaussian0926 program with a two-step strategy. Geometry optimization was performed with the hybrid functional B3LYP27 in the gas phase then followed by single point calculations. The Pd atom was represented by the Stevens/Basch/Krauss effective core potential and associated triple- $\xi$ valence basis set.28-30 The remaining main group atoms were represented by the 6$31+G(d)$ and $6-311++G(d, p)$ basis set for geometry optimizations and single point calculations, respectively. Continuum solvent effects of THF (tetrahydrofuran) and benzene utilized the SMD31 model for the study of dimerization and reductive elimination, respectively. Dispersion effects were compared between GD332 and GD3BJ ${ }^{33}$ methods. Electron density and frontier orbital analyses were performed at the B3LYP/SBK(Pd)/6-311++G(d,p) level of theory at the gasphase optimized geometries. Single point calculations with M06 $^{34}$ and B97D 35 functionals $(6-311++G(d, p)$ basis set $)$ were also carried out at the B3LYP-optimized geometries. Calculations assumed $1 \mathrm{~atm}$ and $243.15 \mathrm{~K}$ unless otherwise noted to simulate the experiments. ${ }^{23}$ Transition states and minima were differentiated on their potential energy surfaces by having one and zero imaginary frequency.

\section{RESULTS AND DISCUSSION}

\section{Geometric Structure of D}

The structure of dimeric complex D was obtained by DFT optimization initiated from the coordinates determined by Xray diffraction (Table $\mathbf{1}$ ). Each of the monomeric $\mathrm{Pd}(\mathrm{II})$ moieties within $\mathbf{D}$ contains one neopentyl ligand, one anilido ligand and one phosphine ancillary ligand: $\mathrm{Ad}_{2} \mathrm{PCH}_{2} \mathrm{CH}_{2} \mathrm{OCH}_{3}$. The phosphine ligands of $\mathbf{D}$ are anti with respect to the $\mathrm{Pd}-\mathrm{Pd}$ vector, while the $\mathrm{NH}$ protons of the anilide are oriented anti to one another. The flexible $-\mathrm{CH}_{2} \mathrm{CH}_{2} \mathrm{OCH}_{3}$ arm points away from the palladium center, and thus this ligand possesses $\kappa$-P instead of the expected $\kappa^{2}-\mathrm{P}, 0$ ligation.

The dimeric core of $\mathbf{D}$ is near planar: the dihedral angles between $\mathrm{Pd}_{1}-\mathrm{N}_{1}-\mathrm{N}_{2}$ and $\mathrm{Pd}_{2}-\mathrm{N}_{1}-\mathrm{N}_{2}$ are $168.4^{\circ}$ and $170.1^{\circ}$ in the calculations and crystal structure, respectively (entry 1 ). The differences between calculated and experimental bond angles are within acceptable ranges $\left(<3.3^{\circ}\right.$, entries $\left.2-5\right)$. Bond distances determined by DFT computations tend to be longer than those determined by X-ray diffraction, although the predicted values are still reasonable. For instance, the optimized $\mathrm{Pd}_{1}-\mathrm{N}_{1}$ bond length is greater than the experimental value by $0.04 \AA(\sim 2 \%$, entry 6$)$. The difference between $\mathrm{Pd}_{1}-\mathrm{N}_{1}$ and $\mathrm{Pd}_{1}-\mathrm{N}_{2}$ is $0.08 \AA$ in the calculations versus $0.03 \AA$ observed from experiments (entries 6 and 7). Moreover, the difference between $\mathrm{Pd}_{2}-\mathrm{N}_{1}$ and $\mathrm{Pd}_{2}-\mathrm{N}_{2}$ is 0.10 and $0.07 \AA$ in the calculations and experiments, respectively, reflecting the difference in the trans influence between phosphine and neopentyl ligands, the difference between dative and covalent $\mathrm{Pd}-\mathrm{N}$ bonds, or a combination of both effects (entries 8 and 9).
The Pd-N bond lengths in dimer $\mathbf{D}$ are not equivalent to each other, based on the calculations and crystal structure.

Notably, the $\mathrm{Pd}_{1}-\mathrm{Pd}_{2}$ distance is 3.42 and $3.33 \AA$ in the calculations and crystal structure of $\mathbf{D}$, respectively (entry 10 ). Considering the van der Waals (vdW) radius of palladium is $1.63 \AA$, 36 the $\mathrm{Pd}_{1}-\mathrm{Pd}_{2}$ distance in $\mathbf{D}$ is longer than the limit of a Pd-Pd vdW interaction (3.26 ̊). In contrast, the largest Pd-Pd distance is $3.19 \AA$ among other known dimeric crystal structures consisting of a $\mathrm{Pd}_{2}(\mu \text {-NHAr })_{2}$ ring.6,25 The metalmetal interaction strength could minimize along the $\mathrm{Pd}-\mathrm{Pd}$ vector in the ring of $\mathbf{D}$.

Table 1. Comparison of D: Calculations vs. Experiments ${ }^{a}$

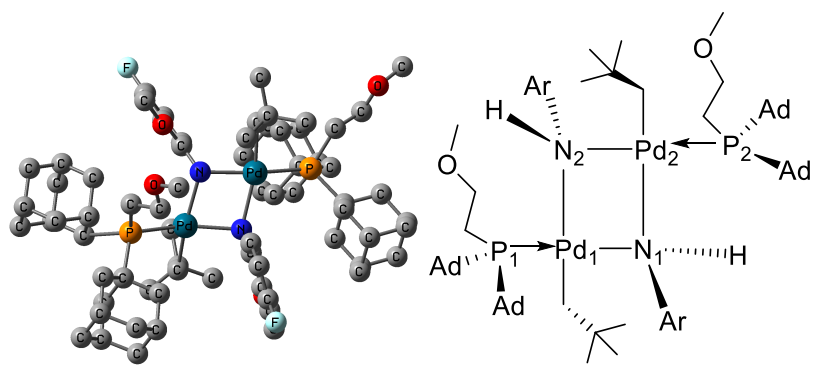

$\begin{array}{ccccc}\text { Entry } & \text { Structure } & \text { Calculations } & \text { Experiments } & \Delta \text { Calc.-Exp. } \\ 1 & \begin{array}{c}\mathrm{Pd}_{1}-\mathrm{N}_{1}-\mathrm{N}_{2}- \\ \mathrm{Pd}_{2}\end{array} & 168.4 & 170.1 & -1.7 \\ 2 & \mathrm{~N}_{1}-\mathrm{Pd}_{1}-\mathrm{P}_{1} & 154.3 & 157.6 & -3.3 \\ 3 & \mathrm{~N}_{1}-\mathrm{Pd}_{2}-\mathrm{P}_{2} & 100.5 & 100.7 & -0.2 \\ 4 & \mathrm{~N}_{2}-\mathrm{Pd}_{2}-\mathrm{P}_{2} & 164.8 & 165.8 & -1.0 \\ 5 & \mathrm{~N}_{2}-\mathrm{Pd}_{1}-\mathrm{P}_{1} & 100.0 & 100.2 & -0.2 \\ 6 & \mathrm{Pd}_{1}-\mathrm{N}_{1} & 2.21 & 2.17 & 0.04 \\ 7 & \mathrm{Pd}_{1}-\mathrm{N}_{2} & 2.29 & 2.20 & 0.09 \\ 8 & \mathrm{Pd}_{2}-\mathrm{N}_{1} & 2.30 & 2.21 & 0.09 \\ 9 & \mathrm{Pd}_{2}-\mathrm{N}_{2} & 2.20 & 2.14 & 0.06 \\ 10 & \mathrm{Pd}_{1}-\mathrm{Pd}_{2} & 3.42 & 3.33 & 0.09\end{array}$

a Optimized geometry of $\mathbf{D}$. Ad: 1-adamantyl. $\mathrm{C}_{\text {neo: }}$ neopentyl. Ar: 4-F-2-( $\left.\mathrm{OCH}_{3}\right)-\mathrm{C}_{6} \mathrm{H}_{3}$. Experimental values from reference 23. Selected angles in degrees and bond distances in Å. Hydrogen atoms are omitted for clarity.

\section{Electronic Structure of D}

The Kohn-Sham frontier molecular orbital contours of dimeric neopentylpalladium(II) amido complex D exhibit strong metal contributions (Figure 2a). The M-L bonding orbitals of the highest occupied molecular orbital (HOMO) are significant among the $\mathrm{Pd}$ and $\mathrm{N}$ atoms of the four-membered ring. Total electron density analysis was also performed for $\mathbf{D}$ (Figure 2b). In the 2-D contour plot, the areas of overlap for the electron density of $\mathrm{Pd}_{2}-\mathrm{N}_{2}$ are greater than those of $\mathrm{Pd}_{2}-\mathrm{N}_{1}$. Furthermore, the 3-D electron density analyses indicate that the density distribution are similar for both $\mathrm{Pd}_{2}-\mathrm{N}_{2}$ and $\mathrm{Pd}_{2}-\mathrm{P}_{2}$ implying that there could be similar bonding character for them (Figure S-1). Finally, both frontier orbital and electron density analyses indicate that the $\mathrm{Pd}-\mathrm{N}$ bonds not identical within the core of $\mathbf{D}$.

a) 


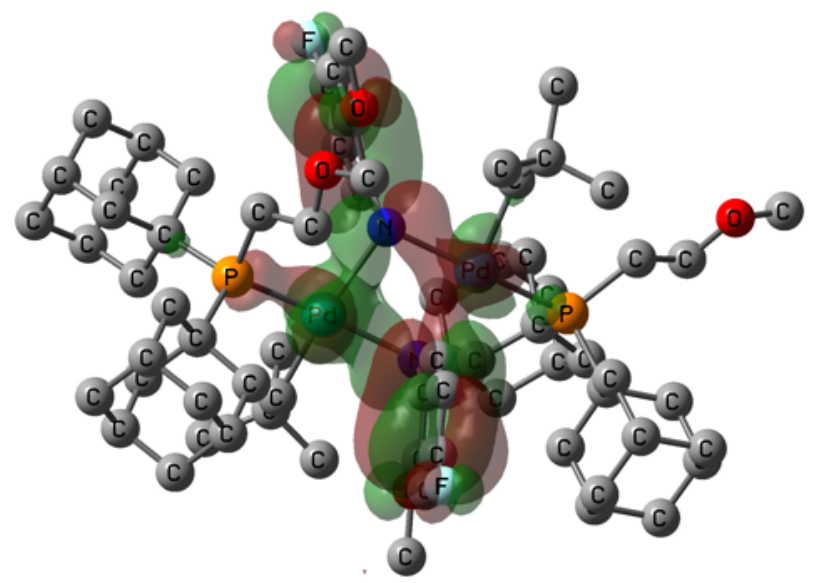

b)

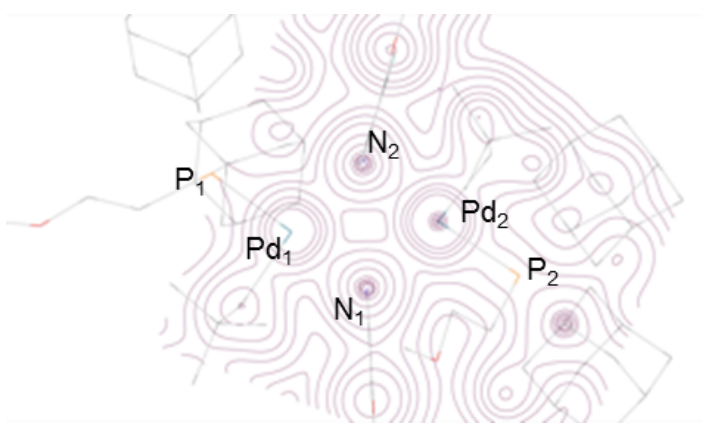

Figure 2. a). Kohn-Sham contours of HOMO with IsoValue = 0.02 . b). 2-D contour of total electron density plot for $\mathbf{D}$ with IsoValue from 0.01 to 0.10 in steps of 0.01 . Hydrogen atoms are omitted for clarity.

\section{Geometric Structures of trans-Monomers}

NMR spectroscopy suggested that the dimer $\mathbf{D}$ and the $\kappa^{2}-\mathrm{P}, 0$ monomer 1 coexist in solution. ${ }^{23}$ However, calculations without dispersion effects predict that the three-coordinate monomer trans-2a with $\kappa$-P coordination would be the ground state, being $2.9 \mathrm{kcal} / \mathrm{mol}$ lower in free energy than 1 (Figure 3, vide infra). Therefore, $\mathbf{1}$ and trans-2a interconvert by a mechanism involving dissociation of the ether arm from palladium. ${ }^{23} \mathrm{~A} \kappa$-P binding mode was also calculated to be the ground state of a monomeric (syn-3-methyl-norborn-2yl)palladium(II) complex containing the same flexible $\mathrm{P}, \mathrm{O}$ ligand in prior work. ${ }^{22}$ Calculations indicated a decrease of the $\mathrm{Pd}-\mathrm{N}$ distance from $\geq 2.20 \AA$ in the dimeric complex $\mathbf{D}$ to $2.02 \AA$ in the monomeric trans-2a. There is more significant impact on the $\mathrm{Pd}-\mathrm{N}$ bonds than other metal-ligand bonds upon dimerization given that they are changing from $\kappa^{-}$to $\mu$ coordination.

$\mathbf{1}^{*}$

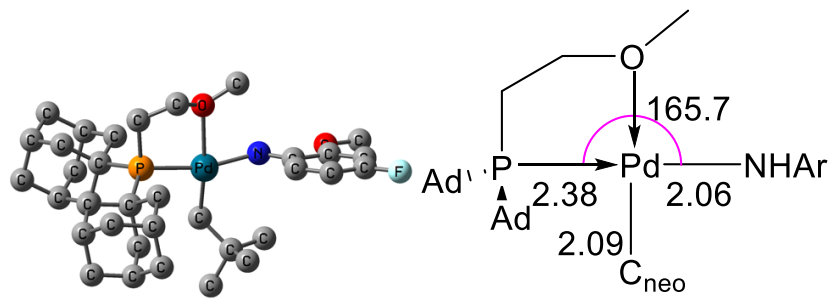

trans-2 $\mathbf{a}^{*}$

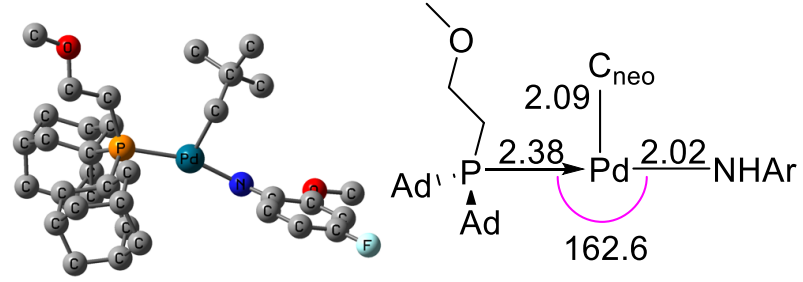

trans-2b
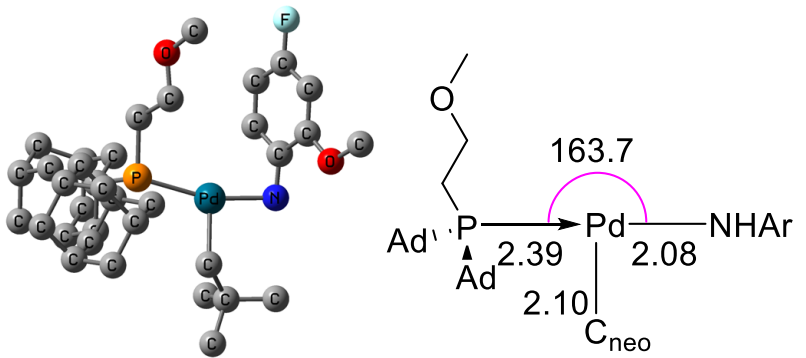

trans-2c
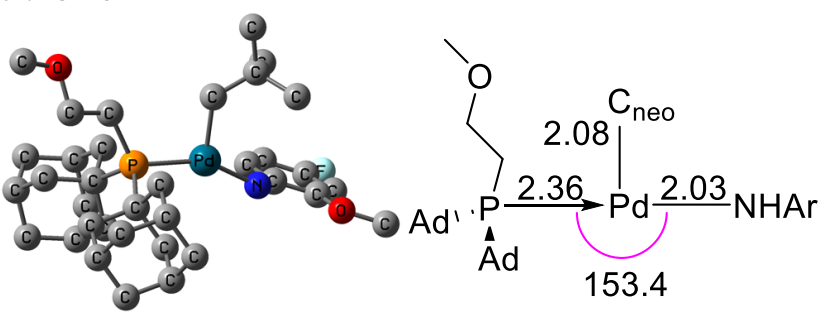

trans-2d
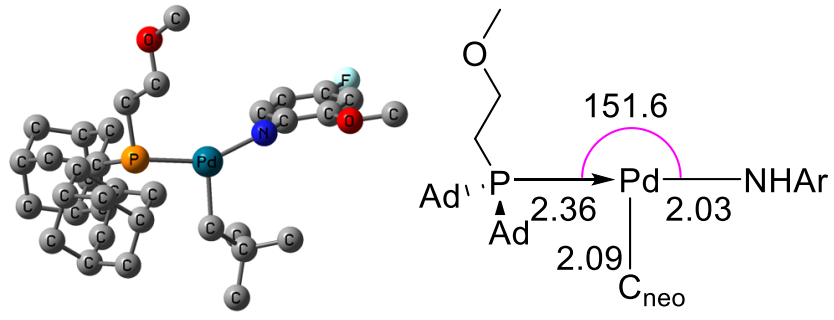

Figure 3. Optimized structures of the trans monomers. Note that trans-2c and trans-2d initially have nitrogen cis to phosphine before geometry optimization. Ad: 1-adamantyl. $\mathrm{C}_{\text {neo: }}$ : neopentyl. Ar: 4-F-2-(OCH$)-\mathrm{C}_{6} \mathrm{H}_{3}$. Selected angles in degrees and bond distances in $\AA$. Hydrogen atoms are omitted for clarity. *Reference 23.

Monomeric neopentylpalladium(II) amido complexes associated with Path I and II are shown in Figure 3. The $\kappa^{2}-\mathrm{P}, 0$ monomer $\mathbf{1}$ is considered as a monomer in Path I because of its trans phosphine and anilide ligands. The structures of transmonomers are summarized in Table 2 . Monomers 1, trans-2a and trans-2b optimized to be T-shaped with a trans P-Pd-N orientation. For example, the angles of $\mathrm{P}-\mathrm{Pd}-\mathrm{N}$ in $\mathbf{1}$, trans-2a and trans-2b were $165.7^{\circ}, 162.6^{\circ}$ and $163.7^{\circ}$, respectively (entry 1). However, attempts to optimize the structures of cis2c and cis-2d starting with nitrogen cis to phosphine (as is require in Path II) were unsuccessful. Upon optimizing the geometry, these yielded trans-2c and trans-2d as minima. For example, the angles of $\mathrm{P}-\mathrm{Pd}-\mathrm{N}$ in optimized trans-2c and trans2d were $153.4^{\circ}$ and $151.6^{\circ}$, respectively. This was expected because the trans influence of the neopentyl ligand is the strongest among the three ligands coordinated to Pd(II), thereby making a three-coordinate complex with nitrogen cis to phosphine unstable. Notably the $\mathrm{Pd}-\mathrm{N}-\mathrm{C}_{\mathrm{ipso}}-\mathrm{C}_{\text {para }}$ dihedral angle for trans-2b was $-32.2^{\circ}$ as compared to those of other 
monomers (Table 2, entry 2). The 2.39, 2.08 and $2.10 \AA$ distances for trans-2b are the longest $\mathrm{Pd}-\mathrm{P}, \mathrm{Pd}-\mathrm{N}$ and $\mathrm{Pd}-\mathrm{C}_{\text {neo }}$ distances, respectively, among all the trans monomers (entries 3 - 5).

Table 2. Optimized Structures of trans-Monomersa

$\begin{array}{lcccccc}\text { Entry } & \text { Structure } & \mathbf{1}^{*} & \mathbf{2 a}^{*} & \mathbf{2 b} & \mathbf{2 c} & \mathbf{2 d} \\ 1 & \mathrm{~N}-\mathrm{Pd}-\mathrm{P} & 165.7 & 162.6 & 163.7 & 153.4 & 151.6 \\ 2 & \begin{array}{c}\text { Pd-N- } \\ \text { Cipso-Cpara }\end{array} & -120.7 & 129.0 & -32.2 & -122.9 & 119.1 \\ & & & & & \\ 3 & \text { Pd-P } & 2.38 & 2.38 & 2.39 & 2.36 & 2.36 \\ 4 & \text { Pd-N } & 2.06 & 2.02 & 2.08 & 2.03 & 2.03 \\ 5 & \text { Pd-Cneo } & 2.09 & 2.09 & 2.10 & 2.08 & 2.09\end{array}$

${ }^{a} C_{n e o}$ : neopentyl. Selected angles in degrees and bond distances in $\AA$. * Reference 23 .

\section{Geometric Structures of Four-Coordinate Monomers}

Although attempts to optimize the structures of complexes containing cis phosphine and anilide ligands (cis-2c and cis-2d) were unsuccessful, it was hypothesized that such complexes could be stabilized by coordination of an additional phosphine or a THF molecule. Experiments were conducted in THF and in the presence of excess phosphine, and therefore the proposed four-coordinate cis complexes might form as intermediates under the experimental conditions. ${ }^{23}$ Therefore, fourcoordinate monomeric neopentylpalladium(II) complexes Table 3. Optimized Structures of Four-coordinate Monomers ${ }^{\mathbf{a}}$ were obtained by ligating either a phosphine ligand (P) or THF (T) to the metal center of three-coordinate monomers; these complexes (3) are expected to be less prone to coordination isomerism as compared to three-coordinate complexes (Table $3)$. In general, the nitrogen is trans to phosphine in complexes $\mathbf{3 a X}$ and $\mathbf{3 b X}(\mathbf{X}=\mathbf{P}$ or $\mathbf{T}$, entries $1-4)$, while the nitrogen is cis to phosphine in $\mathbf{3 c X}$ and $\mathbf{3 d X}$ (entries 5 - 8).

Because of the extra phosphine ligand $\left(\mathrm{P}_{\mathrm{ext}}\right)$, the nitrogen cis to phosphine also presents in $\mathbf{3 a P}$ and $\mathbf{3 b P}$ (entries 1 and 3 ). Note the very long bond distances for Pd-Pext: 6.22 and $6.90 \AA$ in $\mathbf{3 a P}$ and $\mathbf{3 b P}$, respectively, which are beyond the length of a common bond. $\mathbf{3 a P}$ and $\mathbf{3 b P}$ are considered as unstable and can be substituted by trans-2a and trans-2 $\mathbf{2 b}$ in solution, respectively. However, they and other congeners thereafter are marked as "four-coordinate" monomers throughout the paper for convenience of comparison.

Interestingly, the distances for $\mathrm{Pd}-\mathrm{O}_{\mathrm{THF}}$ in $\mathbf{3 a T}$ and $\mathbf{3 b T}$ are 4.73 and $2.58 \AA$, respectively (entries 2 and 4 ). The steric hindrance of 1-adamantyl groups may account for the substantial difference $(2.15 \AA)$. For $3 \mathbf{b T}$, the angle of N-Pd-P is $166.2^{\circ}$ and the $-\mathrm{CH}_{2} \mathrm{CH}_{2} \mathrm{OMe}$ group is pointing to THF (Figure 4). Only 3bT computed to be stable among the monomers originated from the trans-2 monomers.

The distances of Pd-Pext are 2.57 and $2.65 \AA$ A for $\mathbf{3 c P}$ and $\mathbf{3 d P}$, respectively (entries 5 and 7), while the distances of $\mathrm{Pd}-\mathrm{O}_{\mathrm{THF}}$ are 2.39 and $2.37 \AA$ for $\mathbf{3 c T}$ and $\mathbf{3 d T}$, respectively (entries 6 and 8 ). The four-coordinate monomers generated by ligating either $\mathbf{P}$ or $\mathbf{T}$ to the cis-2 structures would be stable from the perspective of bond length.

\begin{tabular}{lccccccc} 
Entry & Complex & $\mathrm{N}-\mathrm{Pd}-\mathrm{P} / \mathrm{P}_{\text {ext }}$ & $\mathrm{Pd}-\mathrm{P}$ & $\mathrm{Pd}-\mathrm{N}$ & $\mathrm{Pd}-\mathrm{C}_{\text {neo }}$ & $\mathrm{Pd}-\mathrm{P}_{\text {ext }}$ & $\mathrm{Pd}-\mathrm{O}_{\text {THF }}$ \\
\hline 1 & $\mathbf{3 a P}$ & $154.7 / 61.2$ & 2.35 & 2.03 & 2.09 & 6.22 & - \\
2 & $\mathbf{3 a T}$ & 162.7 & 2.38 & 2.03 & 2.08 & - & 4.73 \\
3 & $\mathbf{3 b P}$ & $152.9 / 78.7$ & 2.36 & 2.03 & 2.09 & 6.90 & - \\
4 & $\mathbf{3 b T}$ & 166.2 & 2.43 & 2.06 & 2.08 & - & 2.58 \\
5 & $\mathbf{3 c P}$ & $89.0 / 85.7$ & 2.57 & 2.16 & 2.13 & 2.57 & - \\
6 & $\mathbf{3 c T}$ & 98.1 & 2.34 & 2.15 & 2.10 & - & 2.39 \\
7 & $\mathbf{3 d P}$ & $89.5 / 85.3$ & 2.49 & 2.17 & 2.13 & 2.65 & - \\
8 & $\mathbf{3 d T}$ & 95.2 & 2.34 & 2.15 & 2.11 & - & 2.37
\end{tabular}

aPext: extra phosphine ligand. Cneo: neopentyl. Selected bond distances in $\AA$ and bond angles in degrees.

Among the four-coordinate monomers, $\mathbf{3 c P}$ is the precursor leading to $\mathbf{D}$ via Path II (Figure 4). The angles of N$\mathrm{Pd}-\mathrm{P}$ and $\mathrm{N}-\mathrm{Pd}-\mathrm{P}_{\text {ext }}$ are $89.0^{\circ}$ and $85.7^{\circ}$, respectively. The bond distances of $\mathrm{Pd}-\mathrm{P}$ and $\mathrm{Pd}-\mathrm{P}_{\text {ext }}$ are both identical to 2.57 $\AA$. The flexible $-\mathrm{CH}_{2} \mathrm{CH}_{2} \mathrm{OMe}$ arms are pointing in opposite directions. The special arrangement of phosphine ligands in 3cP may stabilize this four-coordinate structure with cis phosphine and anilide ligands (vide infra). However, the dissociation of the extra phosphine ligand could occur prior to or concurrent with dimerization due to its weak bonding with the metal center.
Conformational isomers of four-coordinate monomers were obtained by changing the arrangement of ligands to further investigate possible isomerization effects upon dimerization (Table S-1). For example, the structure of $\mathbf{3} \mathbf{d P}$ is similar to that of $\mathbf{3 c P}$ though the former was generated by rotating the Pd-Pext bond of $\mathbf{3 d P}$. Overall, the formation of four-coordinate monomers is expected to be enhanced by dispersion effects, which have been indicated to stabilize transition metal complexes with bulky ligands. ${ }^{37}$

$3 \mathbf{b T}$ 

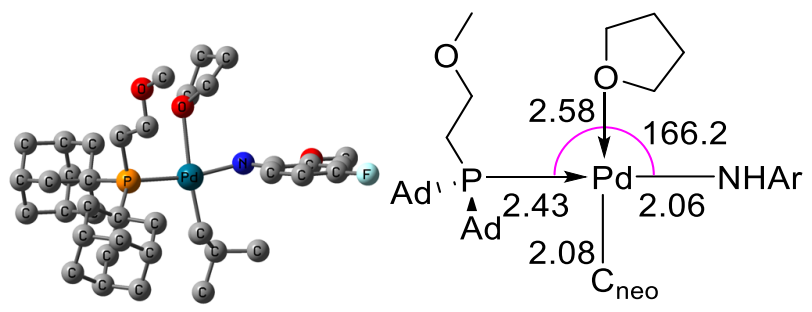

3cP

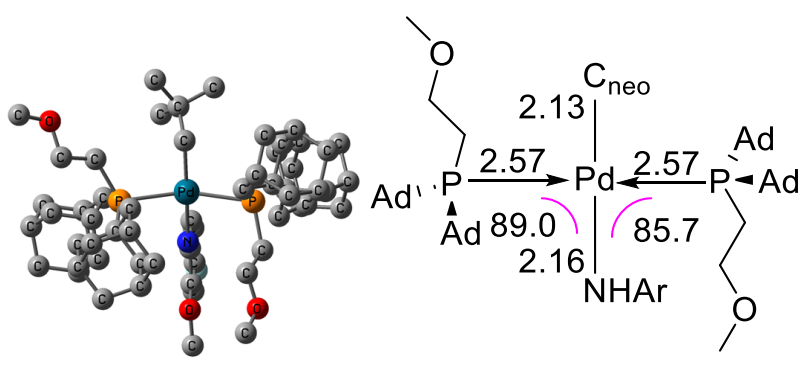

Figure 4. Optimized structures of $\mathbf{3 b T}$ and 3cP. Ad: 1adamantyl. $\mathrm{C}_{n e o}$ : neopentyl. Ar: 4-F-2-(OCH 3$)-\mathrm{C}_{6} \mathrm{H}_{3}$. Selected bond distances in $\AA$ and angles in degrees. Hydrogen atoms are omitted for clarity.

\section{Energetics of Neopentylpalladium(II) Amido Complexes}

The free energies of neopentylpalladium(II) amido complexes are summarized in Figure 5. The results were compared between B3LYP and B3LYP + GD3BJ. The latter incorporated the calculations with dispersion effects via GD3BJ corrections. Isomer trans-2a was set as the free energy origin in both cases.

Calculations without dispersion corrections predicted that the dimer $\mathbf{D}$ was unstable relative to trans-2a $(17.6 \mathrm{kcal} / \mathrm{mol}$ on a per palladium base). This was inconsistent with the experimental results, and we considered that dispersion effects may impact the relative energies of these complexes. Indeed, the free energy of $\mathbf{D}$ is $8.6 \mathrm{kcal} / \mathrm{mol}$ per palladium below trans-2a in the calculations with GD3BJ corrections. The decrease in energy suggests that the favorable $\mathrm{vdW} /$ steric effects could accumulate among the bulky ligands in the dimeric structure.

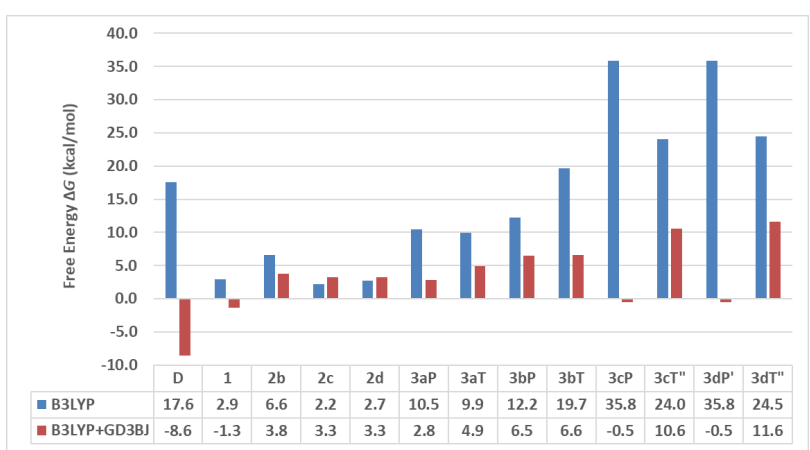

Figure 5. Free energies of the complexes. For $\mathbf{D}: \Delta G=\mathbf{D} / 2$ - 2a. For 1 and $2 u: \Delta G=(1$ or $2 u)-2 a$. For $3 \mathbf{u X :} \Delta G=3 \mathbf{u X}-$ $\mathbf{X}-\mathbf{2 a}$. $2 \mathbf{u}$ and $\mathbf{2 a}$ : trans-monomers. $\mathbf{u}=\mathbf{a}, \mathbf{b}, \mathbf{c}$ or $\mathbf{d}$. $\mathbf{X}=\mathbf{P}$ or T.

In the calculations with B3LYP, the free energy of $\mathbf{1}$ is 2.9 $\mathrm{kcal} / \mathrm{mol}$. For monomers with $\kappa$-P bonding of the dative ligand (trans-2a to trans-2d), the free energies change within $6.6 \mathrm{kcal} / \mathrm{mol}$ when the bonds between metal and ligands are rotated. Monomer trans-2b is less stable than the others because of the twisted anilide ligand. Note trans-2c and trans2d initially bearing nitrogen cis to phosphine both yield a geometry with a roughly trans disposition of these ligands after optimization, thus resulting in free energies that are close to each other $(2.2$ and $2.7 \mathrm{kcal} / \mathrm{mol}$ for trans-2c and trans-2d, respectively).

In contrast, the free energy differences among the studied isomers are more significant for the four-coordinate intermediates in the calculations with B3LYP. For monomers in Path I, the lowest free energy is $9.9 \mathrm{kcal} / \mathrm{mol}$ for 3aT. While in Path II, the free energies for $\mathbf{3 c P}$ and $\mathbf{3 d P}$ are both 35.8 $\mathrm{kcal} / \mathrm{mol}$, which would make them unlikely to form in any appreciable concentration. In addition, monomers with an extra THF (3aT, 3cT"' and 3dT') are more stable than those with an extra phosphine ligand except 3bT, which is 7.5 $\mathrm{kcal} / \mathrm{mol}$ higher than $\mathbf{3 b P}$.

For the three-coordinate monomers, there is no significant change of relative free energies between the results computed with and without GD3BJ. For example, the free energy for trans-2b is $3.8 \mathrm{kcal} / \mathrm{mol}$ in the calculations with GD3BJ corrections. However, the relative (to trans-2a) free energies decrease significantly for the four-coordinate intermediates when considering dispersion effects. For example, the free energies for $\mathbf{3} \mathbf{c P}$ and $\mathbf{3} \mathbf{d P}$ ' are both 0.5 $\mathrm{kcal} / \mathrm{mol}$ below trans-2a.

Calculations incorporating other dispersion effects than GD3BJ were performed for the monomers of interest selected from the dimerization study (Tables $\mathbf{S}-\mathbf{2}$ and $\mathbf{S}-\mathbf{3}$ ). trans-2a was also set as the free energy origin. The free energies of $\mathbf{D}$ are $-7.5,-8.7$ and $-5.3 \mathrm{kcal} / \mathrm{mol}$ per palladium with GD3 corrections, B97D and M06, respectively (Table 4, entry 1). The $\kappa^{2}-\mathrm{P}, 0$ monomer $\mathbf{1}$ is lower than trans-2a in the calculations with dispersion effects except for that with B97D (1.4 kcal/mol, entry 2). Calculations with M06 indicate the lowest free energy is $2.6 \mathrm{kcal} / \mathrm{mol}$ for trans-2b (entry 3). The free energies for trans-2c and trans-2d with B97D are 2.6 and $2.9 \mathrm{kcal} / \mathrm{mol}$, respectively (entries 4 and 5). The lowest free energies for 3aP and $3 \mathbf{b T}$ are $0.6 \mathrm{kcal} / \mathrm{mol}$ with B97D and 6.4 $\mathrm{kcal} / \mathrm{mol}$ with GD3 corrections, respectively (entries 6 and 7). Calculations with B97D indicate that $\mathbf{3 c P}$ and $\mathbf{3 d P}$ are 1.5 $\mathrm{kcal} / \mathrm{mol}$ below trans-2a (entries 8 and 9 ).

To sum up, the differences in energy between 1 and trans2a range from $-1.4 \mathrm{kcal} / \mathrm{mol}$ with $\mathrm{M} 06$ to $2.9 \mathrm{kcal} / \mathrm{mol}$ with B3LYP. The free energy of trans-2 $\mathbf{b}$ is lower than $\mathbf{3 b T}$ though the anilide ligand is twisted in the former. The free energies of $\mathbf{3} \mathbf{c P}$ and $\mathbf{3} \mathbf{d P}$ ' are identical due to their similar structures. Consequently, the energies of the monomers predicted to contribute most significantly to the dimerization process in solution are very sensitive to the dispersion treatment, especially those that differ in coordination number at the palladium. Moreover, the present calculations reveal the importance of dispersion interactions on the relative energies of the monomeric and dimeric complexes (Figure $\mathbf{S}$ 2).

Table 4. Dispersion Effects on Selected Complexesa

\begin{tabular}{lcccc} 
Entry & Complex & B3LYP + GD3 & B97D & M06 \\
\hline 1b & D & -7.5 & -8.7 & -5.3 \\
\hline $2^{\mathrm{b}}$ & $\mathbf{1}$ & -0.5 & 1.4 & -1.4 \\
3 & $\mathbf{2 b}$ & 4.3 & 5.1 & 2.6
\end{tabular}




\begin{tabular}{lllll}
4 & $\mathbf{2 c}$ & 3.5 & 2.6 & 3.7 \\
5 & $\mathbf{2 d}$ & 3.2 & 2.9 & 3.5 \\
6c & $\mathbf{3 a P}$ & 3.1 & 0.6 & 6.6 \\
$7 \mathrm{c}$ & $\mathbf{3 b T}$ & 6.4 & 7.2 & 6.8 \\
\hline 8c & $\mathbf{3 c P}$ & 1.6 & -1.5 & 4.6 \\
$9 \mathrm{c}$ & $\mathbf{3 d \mathbf { P } ^ { \prime }}$ & 1.6 & -1.5 & 4.6
\end{tabular}

aSingle point calculations are performed at the B3LYPoptimized geometries. GD3 dispersion effects augment B3LYP derived free energies. $\Delta G=\mathbf{2 u}-\mathbf{2 a}$. $2 \mathbf{u}$ and $2 \mathbf{a}$ : transmonomers. ${ }^{\mathrm{b}} \Delta G=\mathbf{D} / 2($ or $\mathbf{1})-\mathbf{2 a} \cdot{ }^{\mathrm{c}} \Delta G=\mathbf{3} \mathbf{u X}-\mathbf{X}-\mathbf{2 a} \cdot \mathbf{u}=\mathbf{a}, \mathbf{b}$, c or $\mathbf{d}$. $\mathbf{X}=\mathbf{P}$ or $\mathbf{T}$. Free energy values are reported in $\mathrm{kcal} / \mathrm{mol}$.

\section{Proposed Dimerization Pathways}

In our previous work, the transition state of reductive elimination computed to be $24.6 \mathrm{kcal} / \mathrm{mol}$ above trans-2a $\left(24.7 \mathrm{kcal} / \mathrm{mol}\right.$ from the experiments). ${ }^{23}$ The successful prediction of the energy barrier prompted us to compare the dimer and trans monomers $(\mathbf{1}$, trans-2a and 3bT) under the same conditions (Figure $\mathbf{S}-\mathbf{3}$ and Table $\mathbf{S}-\mathbf{4}$ ). Overall, the impact of dispersion upon reductive elimination barriers is much less than the impact of dispersion upon the calculated dimerization free energies. Only the calculations with dispersion effects corroborate the thermal stability of $\mathbf{D}$.

As noted above, $\mathbf{D}$ is more stable than $\mathbf{1}$, and yet $\mathbf{1}$ undergoes reductive elimination instead of dimerization. ${ }^{23}$ Meanwhile, it is not a thermal neutral process any longer for the dimerization in the calculations. To answer these conundrums, we propose that trans-2 monomers would not react to directly form $\mathbf{D}$, but instead must first proceed through a dimeric isomer such as $\mathbf{Q}$ (Figure 6). There is a stark contrast between $\mathbf{D}$ and $\mathbf{Q}$ : the dative and covalent $\mathbf{P d}-$ $\mathrm{N}$ bonds exchange their positions within the dimeric cores. Because the dative $\mathrm{Pd}-\mathrm{N}$ bonds are flexible to stretch, it remains unclear whether the dimeric core of $\mathbf{Q}$ is planar, near planar (like that of D) or highly puckered (like those of the "Butterfly" dimers in Figure 1a).

On the other hand, calculations optimized another dimeric structure of $\mathbf{D}^{\prime}$ by exchanging the phosphine ligand and neopentyl positions of D (Figure 6 and Table S-5). Total electron density analysis indicated that the dimeric core of $\mathbf{D}^{\prime}$ is similar to that of $\mathbf{D}$ with each palladium center forming a dative bond to the nitrogen trans to the coordinated phosphine (Figure S-4). The free energy of D' is 5.9 - 6.9 $\mathrm{kcal} / \mathrm{mol}$ higher than D per palladium depending on the methods employed (Table S-6). The difference in energy between $\mathbf{D}$ and $\mathbf{D}$ ' indicates that such an isomer as $\mathbf{D}$ ' will be accessed in only very low concentrations.

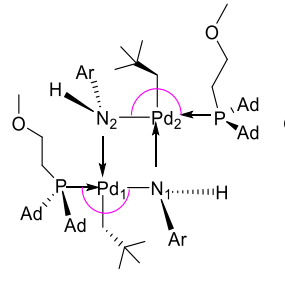

$\mathbf{Q}$

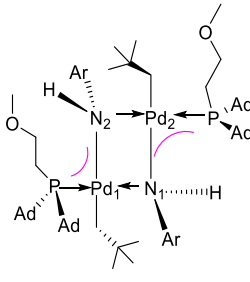

D

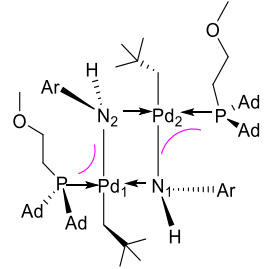

$\mathbf{D}^{\prime}$
Figure 6. Possible dimeric isomers of the neopentylpalladium(II) amido complex. Ar: 4-F-2-(OCH 3$)-$ $\mathrm{C}_{6} \mathrm{H}_{3}$. Ad: 1-adamantyl. Purple line: the angle of $\mathrm{P}-\mathrm{Pd}-\mathrm{N}$.

The proposed dimerization pathways are summarized in Figure 7. For the dimers, $\mathbf{D}$ and $\mathbf{D}$ ' are possible isomers due to the substituents attaching to the ring. In contrast, the significant difference between $\mathbf{D}$ and $\mathbf{Q}$ is their dimeric cores containing dative and covalent $\mathrm{Pd}-\mathrm{N}$ bonds. Moreover, $\mathbf{D}$ is more stable than $\mathbf{Q}$ implying that the conversion from $\mathbf{Q}$ to $\mathbf{D}$ could be favorable and even irreversible. For the possible dimer-monomer equilibrium, $\mathbf{D}$ is more favorable than the cis-2 monomers while $\mathbf{Q}$ is unstable relative to the trans-2 monomers. Among three-coordinate monomers, the cis-2 monomers are less stable than the trans-2 ones due to the strong trans influence of neopentyl group. However, both the extra phosphine and THF can stabilize the structures especially those with nitrogen cis to phosphine in the calculations with dispersion effects. In addition, trans-2a computed to be competitive, which was obtained by moving the ether arm away from the metal center of $\mathbf{1}$ and rotating the $\mathrm{Pd}-\mathrm{C}_{\text {neo }}$ bond.

As the possible intermediates, the cis-2 monomers via Path II might depend on the dissociation of phosphine ligand from the four-coordinate intermediates such as $\mathbf{3 c P}$ and $\mathbf{3 d P}$. Because $\mathbf{3 c P}$ is similar to $\mathbf{3} \mathbf{d P}$, there is actually only one stable monomer with cis $\mathrm{P}, \mathrm{N}$ configuration. While for the monomers with trans $\mathrm{P}, \mathrm{N}$ configuration, two of them are stable: trans-2a and 3bT (or trans-2b). If we assume the equal opportunity for all three stable intermediates to occur and the cis monomer is not interconverted with the trans ones, the ratio of the product will be near 1 to 4 for $\mathbf{D}$ and $\mathbf{1}$, which is consistent with the experiments $(21 \%$ and $79 \%$ for the dimer and monomer, respectively). ${ }^{23}$

Although our calculations strongly suggest that the formation of $\mathbf{D}$ could start with the cis- $\mathbf{2}$ monomers via Path II, there is not yet evidence for those intermediates. Likewise, there is no experimental or computational support for $\mathbf{Q}$ either. However, we cannot exclude the possibility that $\mathbf{Q}$ could be formed by the trans-2 monomers via Path I. Notably, calculations along with the experiments indicated the presence of more species in solution, not just $\mathbf{D}$ and $\mathbf{1 . 2 3}$ Further studies are underway to assess the hypotheses about the cis monomers as well as the dimeric isomer $\mathbf{Q}$.

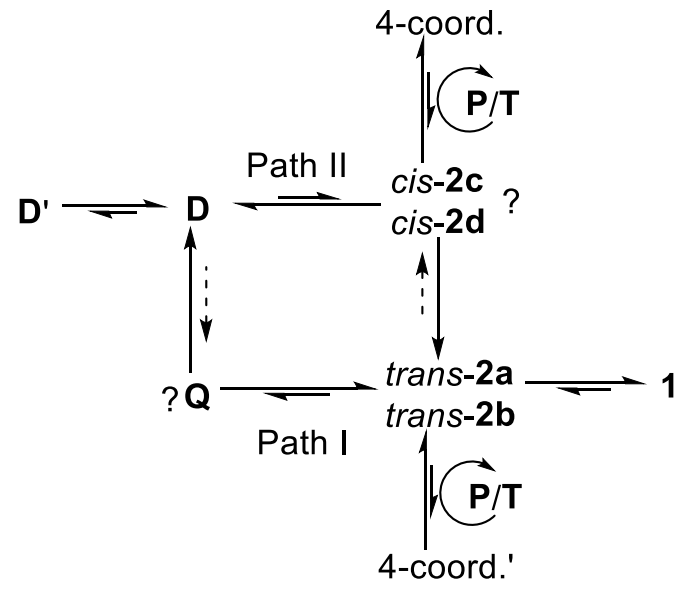

Figure 7. Proposed dimerization pathways. $\mathbf{P}$ and $\mathbf{T}$ are extra phosphine ligand and THF, respectively. 


\section{CONCLUSIONS}

Computational methods were employed to investigate the formation of dimeric neopentylpalladium(II) amido complex D. Both the phosphine ligand and THF have substantial impact on the course of the dimerization. The structure of $\mathbf{D}$ consists of a four-membered ring involving dative and covalent $\mathrm{Pd}-\mathrm{N}$ bonds. The different $\mathrm{Pd}-\mathrm{N}$ bonds within the core were evaluated by electron density and frontier orbital analyses.

Two possible pathways were assessed for dimerization initiated from monomers with different $\mathrm{P}-\mathrm{Pd}-\mathrm{N}$ geometries. However, the three-coordinate monomers bearing nitrogen cis to phosphine were unstable after geometry optimization due to the large trans influence of the neopentyl ligand. To compare the dimerization pathways, the four-coordinate precursors were proposed by coordinating either an extra phosphine ligand or THF to the metal center. The flexible ether arm of phosphine ligand may facilitate the isomerization of complexes as well as the formation of fourcoordinate intermediates.

Calculations without dispersion predict that $\kappa$-P complexes with nitrogen trans to phosphine are the most stable species. The formation of $\mathbf{D}$ is highly endergonic $(17.6 \mathrm{kcal} / \mathrm{mol}$ per palladium relative to trans-2a), which is inconsistent with the experiments. While for the possible four-coordinate intermediates, the large free energies render them inaccessible. For example, the free energies relative to trans$\mathbf{2 a}$ are $35.8 \mathrm{kcal} / \mathrm{mol}$ for both $\mathbf{3 c P}$ and $\mathbf{3 d P}$.

To assess vdW/steric effects from bulky phosphine ligands, dispersion corrections were implemented via single point calculations at the B3LYP gas phase-optimized geometries. Calculations with dispersion effects predict that the $\kappa^{2}-\mathrm{P}, 0$ monomer $\mathbf{1}$ and the four-coordinate intermediates with nitrogen cis to phosphine such as $\mathbf{3} \mathbf{c P}$ and $\mathbf{3} \mathbf{d} \mathbf{P}^{\prime}$ are similar in energy to trans-2a. However, it was not yet a thermal neutral process for the dimerization in the calculations though the free energy of $\mathbf{D}$ is lower than trans-2a (e.g., $-5.3 \mathrm{kcal} / \mathrm{mol}$ per palladium with M06).

Although calculations predict several dimeric isomers for neopentylpalladium(II) amido complexes, there is a single dimer that has been crystallized and characterized. Perhaps the unusual long distance of $\mathrm{Pd}_{1}-\mathrm{Pd}_{2}$ (3.33 $\AA$ in the crystal structure) could limit the delocalization of electrons within the dimeric core resulting in D only. Alternatively, the interconversion among isomeric forms of the dimer in solution is fast on the NMR time scale. Nonetheless, the lonepair electrons of nitrogen can differentiate $\mathbf{D}$ from $\mathbf{Q}$ by forming a dative bond with different metal center within the $\mathrm{Pd}_{2}(\mu \text {-NHAr })_{2}$ ring implying that the $\mathbf{D} / \mathbf{Q}$ isomerism could exist in the dimeric metal complexes with an $\mathrm{M}_{2}(\mu-\mathrm{L})_{2}$ ring.

In summary, competing pathways for the formation of dimeric neopentylpalladium(II) amido complexes were evaluated with computational methods. It is likely that $\mathbf{D}$ could be obtained by the cis-2 monomers via Path II while the trans-2 monomers could form $\mathbf{Q}$ via Path I. Moreover, the absence of dimer-monomer equilibrium between $\mathbf{D}$ and the trans monomers might result in the resistance of the dimer to reductive elimination. Last but not the least, stabilizing threecoordinate monomers cis-2c and cis-2d with an extra ligand to form $\mathbf{3} \mathbf{c P}$ and $\mathbf{3} \mathbf{d P}$ ', respectively, may not only shed light on the mechanism of dimerization, but also benefit future computational studies of transition metal complexes that involve highly reactive species with very bulky ligands for which dispersion effects are critical components of their stability.

\section{ASSOCIATED CONTENT}

Supporting Information. The Supporting Information is available free of charge on the ACS Publications website at DOI:.

Optimized structures of four-coordinate monomers and dimeric isomer, 3-D plots of total electron density analysis, dimerization in the calculations with and without dispersion and Cartesian coordinates $(\AA)$ for the species calculated in this study (PDF).

\section{AUTHOR INFORMATION}

\section{Corresponding Author}

t@unt.edu

\section{Present Addresses}

TQ.J.: Michigan State University, East Lansing, Michigan 48824, United States.

\section{Notes}

The authors declare no competing financial interests.

\section{ACKNOWLEDGMENT}

This research was initiated as a collaboration with the group of Prof. John F. Hartwig (UC-Berkeley) with support from the National Science Foundation Center for Enabling New Technologies through Catalysis (CHE-1205189). The authors thank Prof. John F. Hartwig (UC-Berkeley) for his input, advice and helpful discussion as part of this project. T.R.C. and Q.J. thank the National Science Foundation for providing support through grant CHE-1464943. T.R.C. and Q.J. also acknowledge the National Science Foundation for their support of the UNT CASCaM HPC cluster through grant CHE-1531468. Q.J. thanks Prof. Dr. Kenneth M. Merz Jr. (MSU) for helpful discussions.

\section{REFERENCES}

(1) Noodleman, L. J. Chem. Phys., 1981, 74, 5737-5743.

(2) Hay, P. J.; Thibeault, J. C.; Hoffman, R. J. Am. Chem. Soc., 1975, 97, 4884-4899.

(3) Zhao, P.; Krug, C.; Hartwig, J. F. J. Am. Chem. Soc., 2005, 127, 12066-12073.

(4) Jang, E. S.; McMullin, C. L.; Kä $\beta$, M.; Meyer, K.; Cundari, T. R.; Warren, T. H. J. Am. Chem. Soc., 2014, 136, 10930-10940.

(5) Okeya, S.; Yoshimatsu, H.; Nakamura, Y.; Kawaguchi, S. Bull. Chem. Soc. Jpn. 1982, 55, 483-491.

(6) Villanueva, L. A.; Abboud, K. A.; Boncella, J. M. Organometallics, 1994, 13, 3921-3931.

(7) Ruiz, J.; Martinez, T. M.; Vincente, C.; García, G.; López, G.; Chaloner, P. A.; Hitchcock, P. B. Organometallics, 1993, 12, 43214326.

(8) Driver, M. S.; Hartwig, J. F. J. Am. Chem. Soc., 1997, 119, 8232-8245.

(9) Storr, A.; Penland, A. D. J. Chem. Soc. A, 1971, 1237-1242.

(10) López, G.; Ruiz, J.; García, G.; Vincente, C.; Marti, J. M.; Santana, M. D. J. Organomet. Chem. 1990, 393, C53-C55.

(11) Baird, M. C.; Wilkinson, G. J. Chem. Soc. A, 1967, 865-872. 
(12) Wakatsuki, K.; Tanaka, T. Bull. Chem. Soc. Jpn. 1975, 48, 1475-1477

(13) Beachley, O. T.; Tessier-Youngs, C. Inorg. Chem., 1979, 18, 3188-3191.

(14) Holland, P. L.; Anderson, R. A.; Bergman, R. G. J. Am. Chem. Soc., 1996, 118, 1092-1104.

(15) Stokes, F. A.; Vincent, M. A.; Hiller, I. H.; Ronson, T. K.; Steiner, A.; Wheatley, A. E. H.; Wood, P. T.; Wright, D. S. Dalton Trans., 2013, 42, 13923-13930.

(16) Fan, M.; Duesler, E. N.; Nöth, H.; Paine, R. T. Inorg. Chem., 2010, 49, 2983-2989.

(17) Agnew, N. H.; Appleton, T. G.; Hall, J. R. Inorg. Chim. Acta, 1981, 50, 137-140.

(18) Hartwig, J. F. Acc. Chem. Res., 2008, 41, 1534-1544 and references therein.

(19) Cundari, T. R.; Deng, J. J. Phys. Org. Chem., 2005, 18, 417425.

(20) Hanley, P. S.; Marquard, S. L.; Cundari, T. R.; Hartwig, J. F. J. Am. Chem. Soc., 2012, 134, 15281-15284.

(21) Marquard, S. L.; Rosenfeld, D. C.; Hartwig, J. F. Angew. Chem., Int. Ed., 2010, 49, 793-796.

(22) Peacock, D. M.; Jiang, Q.; Hanley, P. S.; Cundari, T. R.; Hartwig, J. F. J. Am. Chem. Soc., 2018, 140, 4893-4904.

(23) Peacock, D. M.; Jiang, Q.; Cundari, T. R.; Hartwig, J. F. Organometallics, 2018, 37, 3243-3247.
(24) Jiang, Q.; Peacock, D. M.; Hartwig, J. F.; Cundari, T. R. Tetrahedron, 2019, 75, 137-143.

(25) Bruno, I. J.; Cole, J. C.; Edington, P. R.; Kessler, M.; Macrae, C. F., McCabe, P.; Person, J.; Taylor, R. Acta Crystallogr., Sect. B: Struct. Sci. 2002, B58, 389-397.

(26) Gaussian 09 Frisch, M. J.; Trucks, G. W.; Schlegel, H. B., et al. Revision D.01. Wallingford, CT: Gaussian, Inc.: 2013.

(27) Becke, A. D. J. Chem. Phys., 1993, 98, 5648-5652.

(28) Cundari, T. R.; Stevens, W. J. J. Chem. Phys., 1993, 98, $5555-5565$.

(29) Stevens, W. J.; Basch, H.; Krauss, M. J. Chem. Phys., 1984, 81, 6026-6033.

(30) Stevens, W. J.; Krauss, M.; Basch, H.; Jasien, P. G. Can. J. Chem., 1992, 70, 612-630.

(31) Marenich, A. V.; Cramer, C. J.; Truhlar, D. G. J. Phys. Chem. $B, 2009,113,6378-6396$.

(32) Grimme, S.; Antony, J.; Ehrlich, S.; Krieg, H. J. Chem. Phys., 2010, 132, 154104

(33) Grimme, S.; Ehrlich, S.; Goerigk, L. J. Comp. Chem., 2011, 32, 1456-1465.

(34) Zhao, Y.; Truhlar, D. G. Theor. Chem. Acc., 2008, 120, $215-$ 241.

(35) Grimme, S. J. Comp. Chem., 2006, 27, 1787-1799.

(36) Bondi, A. J. Phys. Chem. 1964, 68, 441-451.

(37) Liptrot, J. D.; Guo, J.; Nagase, S.; Power, P. P. Angew. Chem., Int. Ed., 2016, 55, 14766-14769.
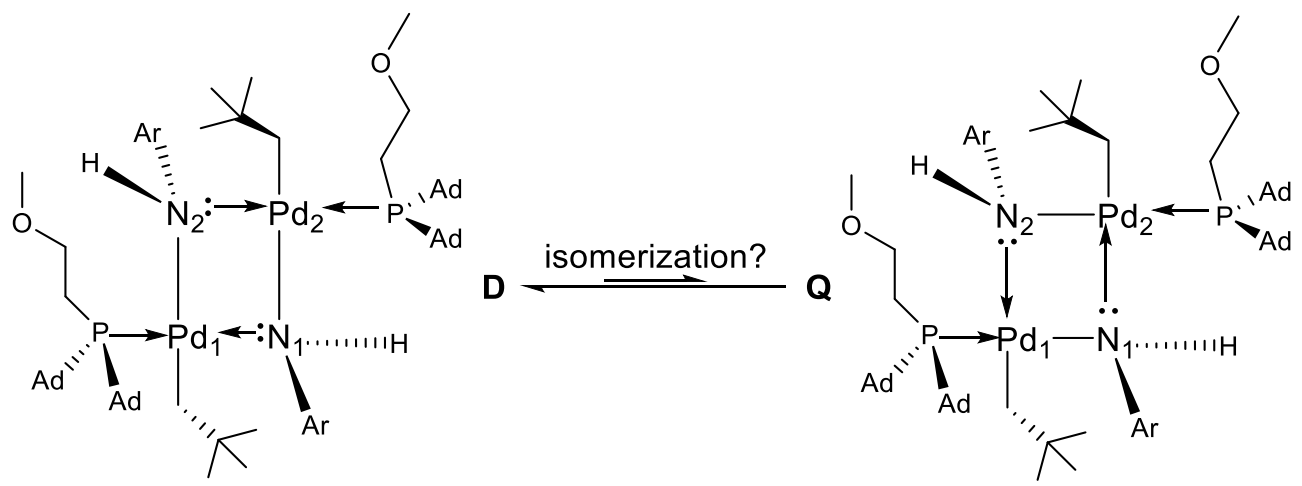

Insert Table of Contents artwork here 